\title{
Changes in Quantitative Muscle Ultrasound for Diagnosis of Intensive Care Unit-Acquired Weakness in Critically III Patients
}

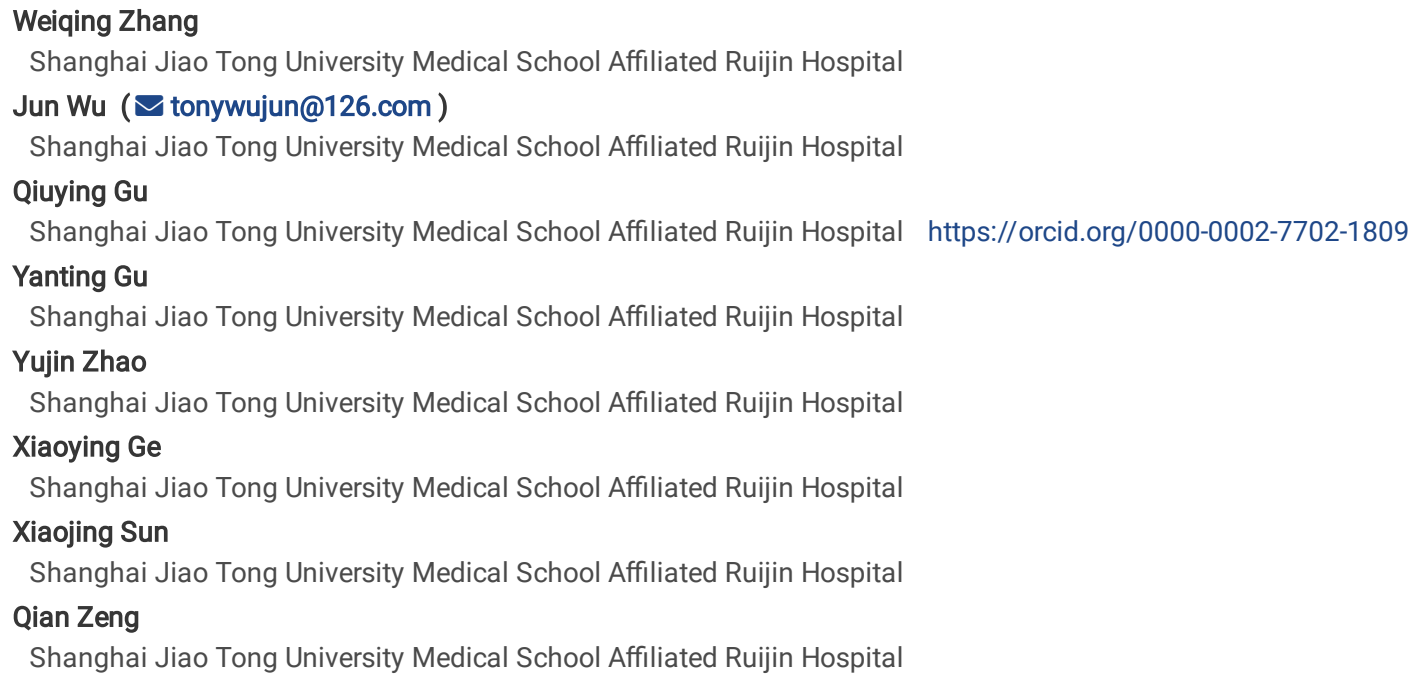

Version of Record: A version of this preprint was published at Scientific Reports on September 14th, 2021. See the published version at https://doi.org/10.1038/s41598-021-97680-y. 


\section{Abstract}

Background: A common occurrence in severe illness is muscle wasting, which is defined as intensive care unit acquired weakness (ICU-AW) and characterized by flaccid tetraparesis with areflexia or hyporeflexia. Many studies revealed the tendency of changes in quantitative muscle ultrasound parameters in critical illnesses; however, the relation between those changes in muscle parameters and intensive care unit acquired weakness was unknown.

Objectives: Using the Medical Research Council Criteria, test the accuracy in diagnosis of changes in quantitative muscle ultrasound for diagnosing intensive care unit acquired weakness.

Methods: Patients who were conscious and positively responded to verbal commands with facial muscles were subjected to quantitative muscle ultrasonography including measuring thickness and cross-sectional area of biceps brachii (BB) muscle, vastus intermedius (VI) muscle, and rectus femoris (RF) muscles for 4 times in the next 10 days after assessing their muscle strength using the Medical Research Council score. Assessment of the diagnostic accuracy of changes in cross-sectional area and thickness of different muscle groups was made using area under the curve of the receiver operating characteristic curve (ROC-AUC). We also calculated specificity, sensitivity, negative predictive value, positive predictive value, and diagnostic accuracy of $15 \%$ threshold for reduction of thickness and $12 \%$ threshold for reduction of cross-sectional area.

Results: 37 patients underwent muscle ultrasonography for 4 times and 24 were found to have ICW-AW. ROC-AUC of changes in muscle parameters were acceptable and ranged from 0.647 to 0.727 . The changes in the thickness of vastus intermedius muscle on both sides while the change in thickness and cross-sectional area of rectus femoris muscle on the right side showed good diagnostic accuracy and ranged from $75.7 \%$ to $78.4 \%$.

Conclusions: Ultrasonography of the changes in muscle parameters with good diagnostic accuracy is an alternative approach for making a diagnosis of intensive care unit acquired weakness. Particularly, changes in the thickness of vastus intermedius muscle on both sides and changes in thickness and crosssectional area of rectus femoris muscle on the right side have diagnostic potential.

\section{Background}

Loss of muscle mass is the clinical manifestation of critical illness neuromyopathy and usually involves bilateral symmetrical limb weakness [1]. It typically defined as intensive care unit acquired weakness (ICU-AW) and presents as flaccid quadriparesis with hyporeflexia or areflexia [2]. The increasing prevalence of reported ICU-AW can be attributed both to an increase in numbers of subjects that survived after having multiple organ dysfunctions and to growing awareness of neuromuscular involvement among intensivists [3]. ICU-AW is very strong indicators of disease severity and can results in a profound impact on outcomes, increasing the extent of mechanical ventilation, prolonging intensive care unit and hospital stay duration, declining long-term functional status, and increasing death rate [4]. This weakness affects half to three-quarters of critically ill patients $[5,6]$. A study states that 1 year after ICU discharge, all patients who were diagnosed with acute respiratory distress syndrome complained of decreased physical function [7]. Patients who survived severe sepsis showed a functional disability and cognitive impairment that persisted for at least 8 years [8]. Aside from these physical and functional impacts, more than $50 \%$ of survivors suffered from mental disorders such as depression or anxiety [9] and were burdened with much higher healthcare costs [10].

Nowadays, using Medical Research Council (MRC) score, comprising six points, diagnosis of ICU-AW can be qualified through strength assessment [11], which in general, is the accepted standard for diagnosis of ICU-AW [12]. The occurrence of ICU-AW is characterized by a mean MRC value under 4 per muscle group (12 muscle groups in total) or MRC sum score under 48 for 12 muscle groups. However, strength assessment needs patients to be conscious, attentive, and able to comprehend simple verbal orders during testing. It is obvious that many critically ill patients will not be able to meet these prerequisites of strength assessment due to serious illness status, mechanical ventilation, and the use of anesthetic medications. Additionally, electrophysiological recordings or muscle biopsy are not routinely carried out in the majority of intensive care units. Consequently, exploration or development of alternative methods or technology for diagnosis of ICU-AW is urgent for intensivists.

Muscle ultrasound is a promising approach to know the muscle changes over time after admission in ICU [13]. Some muscle ultrasound studies have been able to detect reduction tendency of the cross-sectional area (CSA) [14, 15] or decreasing pennation angle [16], decrescent muscle thickness (TH) [14, 17]and increase in echo intensity [18-20] in patients who were critically ill. In order to diagnose the occurrence of ICU-AW, Witteveen 's research tested the accuracy of neuromuscular ultrasound [21]. Although receiver operating characteristics with a calculated area under the curve (ROC-AUC) of muscle parameters was not good enough to differentiate between patients with and without ICU-AW, the study did not test the changes in ultrasound of muscle parameters with time which could possibly have better diagnostic accuracy. Consequently, in the present study, we performed a prospective observational study to test the diagnostic accuracy of the changes in muscle ultrasound over time for the diagnosis of ICU-AW.

\section{Methods}

\section{Population and Design}

The present study designed to be carried out at a single center, a general ICU in Shanghai, China from June 2019 to May 2020 . The study was duly approved by the Ethics Committee of the hospital concerned and informed consent to participate (either directly or through an appropriate surrogate) was taken from all patients. Patients were aged $\geq 18$ years, their anticipated ICU stay was at least 2 days, and was eligible for screening after being evaluated daily for awakening and reaction to simple verbal command. Exclusion patients comprised individuals with prior diagnosed diseases characterized by generalized or regional weakness or with any diagnosis at the time of admission making patients abnormal muscle strength and unable to follow commands (e.g., cardiac arrest, stroke, spinal injury, traumatic brain injury or intracerebral infection), or delirium or dementia during the ICU stay. Additionally, the patients experiencing 
edema of upper and lower limbs and patients who did not have arms or legs for muscle strength testing or ultrasound or had wounds, fractures, lesions, burns, or bleeding at the measurement points were excluded as well.

\section{Clinical data collection}

Baseline data was collected after ICU admission and included age, sex, Body Mass Index (BMI), admission diagnosis, Sequential Organ Failure Assessment (SOFA) score, Acute Physiology and Chronic Health Evaluation II (APACHE II) score, risk factors for polyneuropathy or myopathy (restraints, surgery, nutritional supports, mechanical ventilation, glucose peak concentration, glucocorticoid, use of sedative and analgesic) and comorbidities (cardiac dysfunction, respiratory failure, liver dysfunction, acute kidney injury, hypertension, diabetes mellitus and Multiple Organ Dysfunction Syndrome (MODS)).

\section{Study procedures}

After enrollment, fully conscious patients were assessed for muscle strength by using the MRC score [22]. For the patients mechanically ventilated with sedative, if the RASS (Richmond Agitation Sedation Scale) fell anywhere between -1 and 1 [23] and they showed a positive reaction to 5 verbal commands with facial muscles, we considered them feasible for muscle strength assessment [11]. Twelve muscle groups need to be tested for the calculation of MRC score including elbow flexion, wrist extension, shoulder abduction in upper limbs, and dorsiflexion of the foot, hip flexion knee extension in lower extremities. The function of each muscle group ranged from 0 to 5 and a mean MRC score $<4$ or the total MRC score $<48$ was categorized as the occurrence of ICU-AW in terms of the international consensus statement [12]. The MRC score is extensively utilized for diagnosing the ICU-AW and its good interobserver reliability in critical settings was confirmed in the former study [11].

After strength assessment, other researchers who were trained and blinded for the muscle strength results started to measure the muscle parameters immediately for the first time by using a Philips ultrasound machine (IU22, USA) and a linear transducer or probe (frequency: 10-13MHz) which enabled acquiring images of superficial structures in high resolution [24]. Before performing, the patient must be in a supine position with extended elbows, wrists, knees and relaxed muscles, meanwhile palms and toes of patients were facing or pointing to the ceiling [25]. The muscle parameters for ultrasonography including CSA and TH of biceps brachii (BB) muscle, vastus intermedius (VI) muscle, and rectus femoris (RF) muscles. All the muscles were measured bilaterally and scanned in the transversal (cross-sectional) image. The transducer was oriented transversally in relation to the longitudinal axis of the arm or thigh for obtaining a cross-sectional image, thus creating a right angle to the skin surface. Landmarks for ultrasound image acquisition were at standardized anatomical points, including the midpoint between supraglenoid tubercle and radial tuberosity for BB muscle [26], the second third of the distance between the anterior inferior iliac spine (AIIS) and the midpoint of the proximal border of the patella for RF muscle, and the midline of the same distance as RF muscle for VI muscle [25]. When performing ultrasonography, the pressure to the skin was kept minimal, and adequate coupling agents were used for obtaining the images [3]. In order to enhance the accuracy of the measurement of target muscles, all the CSA and TH were measured three times continuously and an average was calculated as the final value. The whole muscle ultrasound procedure was repeated on day 4 , day 7 , and day 10 to know the changes of these muscle parameters.

\section{Sample size}

According to the equation of diagnostic experiment and our preliminary data [27], 33 examined subjects were found to be sufficient to detect discrimination efficiency in order to provide $90 \%$ power having a value of 0.05 for a two-sided level. We expected the sensitivity and specificity of muscle ultrasonography to be 0.8 . Based on preliminary data, ICU-AW was $50 \%$ prevalent in our critically ill patients. Thus, it was decided upon enrolling 36 subjects, considering the loss of $10 \%$ of the sample.

\section{Statistical analysis}

Kolmogorov-Smirnov's normality test was employed for evaluating continuous variables' distribution. Data acquired from continuous variables with a normal distribution are expressed either as mean and standard deviation or as the interquartile range (IQR) or median in case if they have a non-normal distribution. Mann-Whitney test, Student t-test, exact Fisher test, and chi-squared test were employed to assess the differences among patients with and without ICU-AW diagnosis according to the distribution and type of the variable.

The discriminative power of changes of muscle ultrasound over time was examined with a 95\% confidence interval (CI) using ROC-AUC. The change of CSA and $\mathrm{TH}$ are represented by $\triangle \mathrm{CSA}$ and $\triangle \mathrm{TH}$ respectively, and was calculated using the formula: $\triangle \mathrm{CSA}=\left(\mathrm{CSA}_{\text {day } 10}-\mathrm{CSA}_{\text {day } 1}\right) / \mathrm{CSA}_{\text {day } 1}$ or $\Delta \mathrm{TH}=\left(\mathrm{TH}_{\text {day } 10}-\right.$

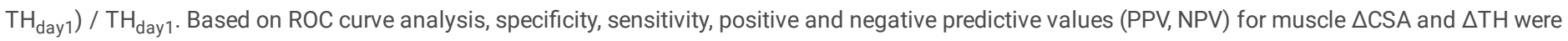
calculated. A significant two-level p-value taken for all analyses was $<0.05$. SPSS version 19 was used to carry out all statistical analyses.

\section{Results}

106 patients enrolled in total and agreed to informed consent, and 37 patients finally went through all 4 times muscle ultrasonography measurement successfully, of whom 24 had ICU-AW. The flowchart of screening and inclusion is shown in Fig 1. Table 1 lists patient characteristics. 
Table 1:

Patient characteristics

\begin{tabular}{|c|c|c|c|c|}
\hline Variable & $\begin{array}{l}\text { No ICU-AW } \\
n=13\end{array}$ & $\begin{array}{l}\text { ICU-AW } \\
n=24\end{array}$ & $t / x^{2} / z$ & $P$ value \\
\hline Gender (\%) & & & 0.794 & 0.373 \\
\hline Male & $9(69.2)$ & $13(54.2)$ & & \\
\hline Female & $4(30.8)$ & $11(45.8)$ & & \\
\hline Age, years (Median (IQR)) & $35(32.5,69.5)$ & $70.5(65.5,78.8)$ & -2.565 & 0.010 \\
\hline BMI $(M \pm S D)$ & $22.85 \pm 3.15$ & $23.15 \pm 3.56$ & -0.250 & 0.804 \\
\hline Diagnosis (\%) & & & 16.207 & 0.001 \\
\hline Sepsis (\%) & $1(7.7)$ & $11(45.8)$ & & \\
\hline Pneumonia (\%) & $1(7.7)$ & $5(20.8)$ & & \\
\hline Severe pancreatitis (\%) & $8(61.5)$ & $1(4.2)$ & & \\
\hline Others (\%) & $3(23.1)$ & $7(29.2)$ & & \\
\hline Surgery & & & 7.309 & 0.017 \\
\hline Yes (\%) & $6(46.2)$ & $21(87.5)$ & & \\
\hline No (\%) & $7(53.8)$ & $3(12.5)$ & & \\
\hline Mechanical Ventilation & & & 18.100 & $\otimes 0.001$ \\
\hline Yes (\%) & $4(30.8)$ & 23(95.8) & & \\
\hline No $(\%)$ & $9(69.2)$ & $1(4.2)$ & & \\
\hline Sedative (\%) & & & 4.220 & 0.040 \\
\hline Yes (\%) & $3(23.1)$ & 14(58.3) & & \\
\hline No (\%) & 10(76.9) & $10(41.7)$ & & \\
\hline Analgesic (\%) & & & 13.017 & 0.001 \\
\hline Yes (\%) & $3(23.1)$ & $20(83.3)$ & & \\
\hline No (\%) & $10(76.9)$ & $4(26.7)$ & & \\
\hline APACHE II Score (M $\pm S D)$ & $14.62 \pm 6.32$ & $22.21 \pm 7.72$ & -3.034 & 0.005 \\
\hline SOFA Score $(\mathrm{M} \pm \mathrm{SD})$ & $3.15 \pm 3.00$ & $9.00 \pm 4.00$ & -4.605 & $凶 0.001$ \\
\hline Vasopressor (\%) & & & 7.537 & 0.006 \\
\hline Yes (\%) & $2(15.4)$ & $15(62.5)$ & & \\
\hline No (\%) & $11(84.6)$ & $9(37.5)$ & & \\
\hline Restraint (\%) & & & 13.017 & 0.001 \\
\hline Yes (\%) & $3(23.1)$ & $20(83.3)$ & & \\
\hline No $(\%)$ & $10(76.9)$ & $4(16.7)$ & & \\
\hline Peak Glucose, mmol/L (M $\pm S D)$ & $11.69 \pm 4.31$ & $12.32 \pm 3.73$ & -0.469 & 0.642 \\
\hline Glucocorticoid (\%) & & & 1.768 & 0.538 \\
\hline Yes (\%) & $0(0)$ & $3(12.5)$ & & \\
\hline No $(\%)$ & $13(100)$ & $21(87.5)$ & & \\
\hline Nutritional support (\%) & & & 1.377 & 0.440 \\
\hline Yes (\%) & $11(84.6)$ & $16(66.7)$ & & \\
\hline No $(\%)$ & $2(15.4)$ & $8(33.3)$ & & \\
\hline Hypertension & & & 5.247 & 0.022 \\
\hline Yes (\%) & $3(23.1)$ & $15(62.5)$ & & \\
\hline No $(\%)$ & $10(76.9)$ & $9(37.5)$ & & \\
\hline
\end{tabular}

Page $4 / 10$ 


\begin{tabular}{|c|c|c|c|c|}
\hline Diabetes (\%) & & & 3.012 & 0.119 \\
\hline Yes (\%) & $1(7.7)$ & $8(33.3)$ & & \\
\hline No (\%) & $12(92.3)$ & $16(66.7)$ & & \\
\hline Cardiac dysfunction (\%) & & & 2.295 & 0.216 \\
\hline Yes (\%) & $1(92.3)$ & $7(29.2)$ & & \\
\hline No (\%) & $12(7.7)$ & $17(70.8)$ & & \\
\hline Respiratory failure (\%) & & & 12.103 & 0.001 \\
\hline Yes (\%) & $5(38.5)$ & 22(91.7) & & \\
\hline No (\%) & $8(61.5)$ & $2(8.3)$ & & \\
\hline Acute kidney injury (\%) & & & 1.279 & 0.305 \\
\hline Yes (\%) & $3(23.1)$ & $10(41.7)$ & & \\
\hline No (\%) & $10(76.9)$ & $14(58.3)$ & & \\
\hline Liver dysfunction (\%) & & & 0.426 & 0.724 \\
\hline Yes (\%) & $4(30.8)$ & $10(41.7)$ & & \\
\hline No (\%) & $9(69.2)$ & $14(58.3)$ & & \\
\hline MODS (\%) & & & 8.479 & 0.003 \\
\hline Yes (\%) & $0(0)$ & $11(45.8)$ & & \\
\hline No (\%) & $13(100)$ & $13(54.2)$ & & \\
\hline
\end{tabular}

ICU-AW: intensive care unit acquired weakness; BMI: Body Mass Index; APACHE II: Acute Physiology and Chronic Health Evaluation II; SOFA: Sequential Organ Failure Assessment; M: mean; SD: standard deviation; IQR: interquartile range; MODS: Multiple Organ Dysfunction Syndrome

Whether or not patients suffered from ICU-AW, the groups all presented a descending trend of both TH and CSA bilaterally. In the upper limbs, only the changes of CSA in BB muscle on the right side showed a statistical difference in ICU-AW patients and non-ICU-AW individuals. Moreover, ICU-AW patients had an obviously greater degree of declination in CSA of RF muscle bilaterally, and a remarkable reduction of TH in VI muscle as well (Table 2).

Table 2:

Repetitive measures analysis of muscles thickness and cross-sectional area in patients with or without ICU-AW

\begin{tabular}{|c|c|c|c|c|c|c|c|c|c|}
\hline \multirow[t]{4}{*}{ Muscles } & \multirow[t]{4}{*}{ Lateral } & \multirow[t]{4}{*}{ Variable } & \multicolumn{2}{|l|}{ Day1 } & \multicolumn{2}{|l|}{ Day4 } & \multicolumn{2}{|l|}{ Day7 } & \multirow{2}{*}{$\begin{array}{l}\text { Day10 } \\
\text { No ICU-AW }\end{array}$} \\
\hline & & & No ICU-AW & ICU-AW & No ICU-AW & ICU-AW & No ICU-AW & ICU-AW & \\
\hline & & & $\mathrm{M} \pm \mathrm{SD}$ & $\mathrm{M} \pm \mathrm{SD}$ & $\mathrm{M} \pm \mathrm{SD}$ & $M \pm S D$ & $\mathrm{M} \pm \mathrm{SD}$ & $\mathrm{M} \pm \mathrm{SD}$ & $\mathrm{M} \pm \mathrm{SD}$ \\
\hline & & & /Median (IQR) & /Median (IQR) & /Median (IQR) & /Median (IQR) & /Median (IQR) & /Median (IQR) & /Median (IC \\
\hline \multirow[t]{4}{*}{ BB } & \multirow[t]{2}{*}{ Left } & $\mathrm{TH}$ & $1.80 \pm 0.44$ & $1.79 \pm 0.50$ & $1.76 \pm 0.42$ & $1.55 \pm 0.43$ & $1.73 \pm 0.50$ & $1.57 \pm 0.47$ & $1.67 \pm 0.43$ \\
\hline & & CSA & $6.46 \pm 1.98$ & $5.60 \pm 1.80$ & $6.06 \pm 1.68$ & $5.19 \pm 1.99$ & $6.36 \pm 0.48$ & $4.90 \pm 1.82$ & $5.72 \pm 1.66$ \\
\hline & \multirow[t]{2}{*}{ Right } & $\mathrm{TH}$ & $1.85 \pm 0.54$ & $1.75 \pm 0.47$ & $1.79 \pm 0.43$ & $1.54 \pm 0.42$ & $1.83 \pm 0.45$ & $1.48 \pm 0.47$ & $1.73 \pm 0.43$ \\
\hline & & CSA & $6.56 \pm 2.19$ & $5.57 \pm 1.67$ & $6.57 \pm 2.26$ & $5.13 \pm 1.77$ & $6.51 \pm 2.30$ & $5.00 \pm 1.72$ & $6.24 \pm 1.98$ \\
\hline \multirow[t]{4}{*}{ RF } & \multirow[t]{2}{*}{ Left } & $\mathrm{TH}$ & $1.47 \pm 0.41$ & $1.37 \pm 0.42$ & $1.45 \pm 0.42$ & $1.22 \pm 0.37$ & $1.37 \pm 0.48$ & $1.15 \pm 0.37$ & $1.40 \pm 0.47$ \\
\hline & & CSA & $5.59(4.59,8.31)$ & $5.19(4.28,5.63)$ & $5.79(4.04,8.10)$ & $4.70(3.53,5.48)$ & $6.24(4.33,8.36)$ & $4.25(3.90,5.54)$ & $5.93(4.30,7$ \\
\hline & \multirow[t]{2}{*}{ Right } & $\mathrm{TH}$ & $1.40 \pm 0.40$ & $1.31 \pm 0.44$ & $1.42 \pm 0.44$ & $1.19 \pm 0.35$ & $1.43 \pm 0.41$ & $1.13 \pm 0.42$ & $1.41 \pm 0.43$ \\
\hline & & CSA & $5.90(4.63,7.74)$ & $4.85(4.17,5.44)$ & $5.65(4.23,7.57)$ & $4.53(3.81,5.16)$ & $5.78(4.68,7.77)$ & $4.11(3.12,5.05)$ & $5.85(4.31,7$ \\
\hline \multirow[t]{2}{*}{ VI } & Left & $\mathrm{TH}$ & $0.84(0.73,1.28)$ & $0.65(0.56,0.95)$ & $0.81(0.61,1.32)$ & $0.58(0.44,0.71)$ & $0.79(0.61,1.14)$ & $0.54(0.38,0.64)$ & $0.75(0.57,1$ \\
\hline & Right & $\mathrm{TH}$ & $0.90(0.66,1.10)$ & $0.70(0.52,0.87)$ & $0.81(0.57,1.22)$ & $0.63(0.43,0.79)$ & $0.90(0.57,1.16)$ & $0.54(0.41,0.72)$ & $0.85(0.52,1$ \\
\hline
\end{tabular}

ICU-AW: intensive care unit acquired weakness; BB: biceps brachii; RF: rectus femoris; VI: vastus intermedius; TH: thickness; CSA: cross-sectional area; M: mean; SD: standard deviation; IQR: interquartile range; 
$\triangle \mathrm{TH}$ of BB muscle on both sides had higher ROC-AUC than CSA, but $\triangle \mathrm{CSA}$ of RF muscle had higher ROC-AUC than TH, especially on the right side. $\triangle \mathrm{TH}$ and $\triangle \mathrm{CSA}$ of RF muscle on the right side showed the highest ROC-AUC which was 0.840 and 0.888 respectively. Additionally, $\triangle T H$ of VI muscle also presented good diagnostic value for the diagnosis of ICU-AW. (Table 3, Figure 2 \&3).

Table 3:

Receiver Operating Characteristic curves of changes in thickness and cross-sectional area of muscles over time

\begin{tabular}{|c|c|c|c|c|c|c|c|}
\hline \multirow[t]{2}{*}{ Muscles } & \multirow[t]{2}{*}{ Lateral } & \multirow[t]{2}{*}{ Variable } & \multirow[t]{2}{*}{ ROC-AUC } & \multirow[t]{2}{*}{ SE } & \multirow[t]{2}{*}{$\mathrm{P}$} & \multicolumn{2}{|c|}{$95 \%$ CI for ROC-AUC } \\
\hline & & & & & & lower & upper \\
\hline \multirow[t]{4}{*}{ BB } & \multirow[t]{2}{*}{ Left } & $\Delta \mathrm{TH}$ & 0.708 & 0.095 & 0.039 & 0.523 & 0.894 \\
\hline & & $\triangle \mathrm{CSA}$ & 0.647 & 0.092 & 0.143 & 0.466 & 0.828 \\
\hline & \multirow[t]{2}{*}{ Right } & $\Delta \mathrm{TH}$ & 0.756 & 0.078 & 0.011 & 0.603 & 0.910 \\
\hline & & $\triangle \mathrm{CSA}$ & 0.676 & 0.090 & 0.080 & 0.500 & 0.852 \\
\hline \multirow[t]{4}{*}{ RF } & \multirow[t]{2}{*}{ Left } & $\Delta \mathrm{TH}$ & 0.696 & 0.092 & 0.052 & 0.515 & 0.876 \\
\hline & & $\Delta \mathrm{CSA}$ & 0.699 & 0.088 & 0.049 & 0.527 & 0.870 \\
\hline & \multirow[t]{2}{*}{ Right } & $\Delta \mathrm{TH}$ & 0.840 & 0.068 & 0.001 & 0.707 & 0.972 \\
\hline & & $\triangle \mathrm{CSA}$ & 0.888 & 0.052 & $\nabla 0.001$ & 0.785 & 0.990 \\
\hline \multirow[t]{2}{*}{$\mathrm{VI}$} & Left & $\Delta \mathrm{TH}$ & 0.785 & 0.074 & 0.005 & 0.640 & 0.931 \\
\hline & Right & $\Delta \mathrm{TH}$ & 0.779 & 0.086 & 0.006 & 0.611 & 0.947 \\
\hline
\end{tabular}

BB: biceps brachii; RF: rectus femoris; Vl: vastus intermedius; $\triangle \mathrm{TH}$ : changes in thickness; $\triangle \mathrm{CSA}$ : changes in cross-sectional area; SE: standard error; ROC-AUC: receiver operating characteristic curves with calculated area under the curve; Cl: confidence interval;

Further, using specific thresholds ( $15 \%$ for $\triangle \mathrm{TH}$ of BB, RF and VI muscle, $12 \%$ for $\triangle \mathrm{CSA}$ of BB and RF muscle) in term of Youden Index of $\Delta \mathrm{TH}$ and $\Delta \mathrm{CSA}$ that were calculated based on the ROC curve, sensitivity, specificity, PPV, NPV, and accuracy were confirmed and presented in Table 4 . Diagnostic accuracy of $\triangle T H$ and $\triangle \mathrm{CSA}$ of RF muscle on the right side and $\triangle \mathrm{TH}$ of VI muscle on both sides was high and ranged from $75.7 \%$ to $78.4 \%$.

Table 4:

specificity, sensitivity, negative predictive value, positive predictive value and accuracy for defined cutoffs of changes of thickness and cross-sectional area of muscles over time

\begin{tabular}{|c|c|c|c|c|c|c|c|c|}
\hline Muscles & Lateral & Variable & Cutoff & Sensitivity (\%) & Specificity (\%) & PPV (\%) & NPV (\%) & Accuracy (\%) \\
\hline \multirow[t]{4}{*}{ BB } & \multirow[t]{2}{*}{ Left } & $\Delta \mathrm{TH}$ & $15 \%$ & $36.5 \%$ & $76.9 \%$ & $80.0 \%$ & $45.5 \%$ & $59.5 \%$ \\
\hline & & $\triangle \mathrm{CSA}$ & $12 \%$ & $66.7 \%$ & $46.2 \%$ & $66.7 \%$ & $38.5 \%$ & $56.8 \%$ \\
\hline & \multirow[t]{2}{*}{ Right } & $\Delta \mathrm{TH}$ & $15 \%$ & $58.3 \%$ & $76.9 \%$ & $83.3 \%$ & $52.6 \%$ & $67.6 \%$ \\
\hline & & $\triangle \mathrm{CSA}$ & $12 \%$ & $58.3 \%$ & $84.6 \%$ & $82.4 \%$ & $50.0 \%$ & $64.9 \%$ \\
\hline \multirow[t]{4}{*}{ RF } & \multirow[t]{2}{*}{ Left } & $\Delta \mathrm{TH}$ & $15 \%$ & $58.3 \%$ & $76.9 \%$ & $83.3 \%$ & $52.6 \%$ & $67.6 \%$ \\
\hline & & $\triangle \mathrm{CSA}$ & $12 \%$ & $58.3 \%$ & $76.9 \%$ & $50.0 \%$ & $47.4 \%$ & $62.2 \%$ \\
\hline & \multirow[t]{2}{*}{ Right } & $\Delta \mathrm{TH}$ & $15 \%$ & $70.8 \%$ & $84.6 \%$ & $89.5 \%$ & $61.1 \%$ & $75.7 \%$ \\
\hline & & $\triangle \mathrm{CSA}$ & $12 \%$ & $70.8 \%$ & $100 \%$ & $70.8 \%$ & $84.6 \%$ & $75.7 \%$ \\
\hline \multirow[t]{2}{*}{ VI } & Left & $\Delta \mathrm{TH}$ & $15 \%$ & $79.2 \%$ & $69.2 \%$ & $82.6 \%$ & $64.3 \%$ & $75.7 \%$ \\
\hline & Right & $\Delta \mathrm{TH}$ & $15 \%$ & $83.3 \%$ & $69.2 \%$ & $83.3 \%$ & $69.2 \%$ & $78.4 \%$ \\
\hline
\end{tabular}

BB: biceps brachii; RF: rectus femoris; Vl: vastus intermedius; $\triangle \mathrm{TH}$ : changes in thickness; $\triangle \mathrm{CSA}$ : changes in cross-sectional area; PPV: positive predictive values; NPV: negative predictive values;

\section{Discussion}

The monitoring and diagnosis of ICU-AW are challenging in ventilated and sedated ICU patients because clinical examination of strength particularly needs cooperation from patients, which is an obvious disadvantage in evaluation $[19,28]$. In contrast, muscle ultrasound is a non-invasive, painless, and commonly used bedside technique that is entirely independent of patient cooperation. It is hence of great significance for assessing and monitoring muscular waste in critically ill patients $[13,21]$. The present study confirmed that patients with ICU-AW had a significant reduction of muscle TH and CSA than those of patients 
without ICU-AW, especially in the lower extremities. Moreover, for a $15 \%$ threshold for reduction of TH and a $12 \%$ threshold for reduction of CSA, muscles in lower extremities showed good diagnostic accuracy of the diagnosis of ICU-AW, particularly on the right side.

In this study, of all evaluated patients, $64.9 \%$ were found to have ICU-AW. Whether or not patients had ICU-AW, all patients presented the descending trend of both TH and CSA bilaterally. Moreover, patients with ICU-AW had an obviously greater degree of declination in CSA of RF muscle bilaterally, and a remarkable reduction of TH in VI muscle of both sides as well. Turton et al. carried out a study on 22 ICU patients who were mechanically ventilated and performed an ultrasonographic assessment of the flexor compartment of the elbow joint, the vastus lateral muscle and the medial head of the gastrocnemius muscle on admission and 10 days later. The results showed that the loss of muscle mass mainly occurred in the lower extremities and there was no change in the size of the flexor compartment of the elbow joint. Such data helps to justify the argument regarding investigating the lower extremities further as peripheral muscles, in patients with critical illnesses have more chances to undergo early disuse atrophy [29]. In particular, a 3-week follow-up study employed ultrasonography to evaluate RF muscle in terms of the morphological changes and found severe muscle mass loss in CSA and muscle diameter experienced by all the ICU trauma patients. By day 20 , approximately $45 \%$ of RF muscle mass was lost [30]. Consequently, in comparison to upper limbs, lower limbs muscles experience earlier and greater atrophy. The potential reason was given in an earlier study that assessed CSA of RF muscle and protein/DNA ratio over time. The results showed that during the first week virtually all cases decreased in muscle mass. Lower limb muscle atrophy is considered to be the result of net catabolism due to the decrease of muscle protein synthesis and the simultaneous increase of protein decomposition relative to protein synthesis [15].

Few previous studies tested muscle ultrasonography for the diagnosis of ICU-AW or prediction of prognosis or similar symptoms. One study diagnosed skeletal muscle loss by measuring the CSA of RF muscle using ultrasound and compared it with frailty to predict the prognosis of critically ill patients. The outcomes of the study clearly show that the prediction value of adverse discharge tendency by bedside ultrasound in the diagnosis of skeletal myopenia was consistent with frailty [31]. Moreover, a prospective observational study found that larger the CSA of RF muscle on the day of admission, lower the occurrence of the muscle fiber necrosis and muscle waste of RF muscle [18]. In addition, Greening et al. demonstrated that an independent risk factor for unscheduled readmission or death is a smaller quadriceps muscle size measured by ultrasound [32]. These studies showed the potential diagnostic value for ICU-AW diagnosis. However, these studies did not test the possibility of discrimination value of the muscle parameters by ultrasound between patients with and without ICU-AW. Witteveen's study performed ultrasonographic TH of tibialis anterior muscle, BB muscle, flexor carpi radialis muscle, and RF muscle thus finding that for these muscles, the diagnostic accuracy of muscle parameters was rather low with ROC-AUC ranging from 51.3 to $68.0 \%$ [21]. Nevertheless, the study failed to observe the changes in muscle parameters over time, and CSA which is considered as a crucial property for contraction and strength of muscle was not involved in the study [13]. To the best of our knowledge, the present study is the first of its kind testing the usefulness of changes in muscle parameters by using ultrasound to diagnose ICU-AW. According to results, the changes in quantitative muscle ultrasound had good performance when analyzed on MRC criteria for the diagnosis of ICU-AW, which endorses the use of muscle ultrasound as a surrogate tool for ICU-AW diagnosis. We also confirmed that the best cutoff value of reduction in muscle parameters for diagnosing ICU-AW using ultrasound is more than $15 \%$ for $\mathrm{TH}$ in $\mathrm{VI}$ muscle and more than $12 \%$ for CSA in RF muscle of the right side.

The findings of the present study confirmed that muscle ultrasound is an alternative approach for earlier recognition of ICU-AW, especially the unconscious patients who are not suitable for strength assessment. However, some limitations of this study deserve the necessary commentary. First, due to the limited availability of biopsy or electroneuromyography in the ICU, we could not classify patients with ICU-AW into the three subcategories (critical illness neuromyopathy (CINM), critical illness myopathy (CIM) and critical illness polyneuropathy (CIP)). Second, we did not observe other ultrasonographic characteristics of muscle in recognition of ICU-AW, for instance, pennation angle and echo intensity which may have better diagnostic value. Last but not the least, it was impossible for ultrasound examiners to be completely blind to the MRC score because the absence or presence of spontaneous movements gave the impression of muscle strength. Therefore, in order to improve the accuracy of muscle measurement, all CSA and TH were measured three times in a row, and the average value is calculated as the final value to minimize the performer's deviation.

\section{Conclusion}

Ultrasound measurement of muscles is an alternative tool for management and recognition of ICU-AW. Changes in TH and CSA of RF muscle on the right side and the changes in TH of VI muscle on both sides had good diagnostic accuracy for diagnosis of ICU-AW.

\section{Declarations}

\section{Ethics approval and consent to participate}

The study was reviewed and approved by the Ethics Committee of the Rui Jin hospital (Reference Number 2018-90) in August 2018.

Written informed consent was obtained from all participants or their immediate relatives.

\section{Competing interests}

The authors declare that they have no competing interests.

\section{Consent for publication}

By giving written informed consent, participants have provided their permission for storage of data and publication of the study results. All authors consent to publication.

Availability of data and material 
The data generated from this study will be made available on request to the corresponding authors.

Funding

This study was funded by a grant from School of Medicine, Shanghai Jiao Tong University under its Back-up Personnel Training Program (Grant Reference Number Hlgy1801 kyx) and a grant for Nursing Research of Rui Jin Hospital (Grant Reference Number RJHK-2018-10).

\section{Authors' contributions}

WQZ contributed to design and study protocol preparation, and prepared the manuscript's first draft, and was responsible for set-up and day-to-day conduct of study at the department, and obtained funding from School of Medicine, Shanghai Jiao Tong University. JW contributed to design and study protocol preparation, and trained YJZ, QZ, QL in ultrasound assessment. QYG contributed to design and study protocol preparation, and facilitated set-up of study at site, and was involved in manuscript preparation. YTG prepared the Statistical Analysis Plan, was involved in manuscript preparation and was involved in the statistical analysis of the data. YJZ, XYG, XJS, QZ were responsible for day-to-day conduct of study at the department, and assisted in authoring the manuscript. All authors read and approved the final manuscript.

\section{Acknowledgements}

The authors would like to thank medical staff in the department of critical care medicine at the Rui Jin hospital.

\section{References}

1. Kress JP, Hall JB: ICU-acquired weakness and recovery from critical illness. N Engl J Med 2014, 370(17):1626-1635.

2. Stevens RD, Dowdy DW, Michaels RK, Mendez-Tellez PA, Pronovost PJ, Needham DM: Neuromuscular dysfunction acquired in critical illness: a systematic review. Intensive Care Med 2007, 33(11):1876-1891.

3. Hermans G, Van den Berghe G: Clinical review: intensive care unit acquired weakness. Crit Care 2015, 19:274.

4. Ali NA, O'Brien JM, Jr., Hoffmann SP, Phillips G, Garland A, Finley JC, Almoosa K, Hejal R, Wolf KM, Lemeshow S et al: Acquired weakness, handgrip strength, and mortality in critically ill patients. Am J Respir Crit Care Med 2008, 178(3):261-268.

5. Connolly BA, Jones GD, Curtis AA, Murphy PB, Douiri A, Hopkinson NS, Polkey MI, Moxham J, Hart N: Clinical predictive value of manual muscle strength testing during critical illness: an observational cohort study. Crit Care 2013, 17(5):R229.

6. Kasotakis G, Schmidt U, Perry D, Grosse-Sundrup M, Benjamin J, Ryan C, Tully S, Hirschberg R, Waak K, Velmahos G et al: The surgical intensive care unit optimal mobility score predicts mortality and length of stay. Crit Care Med 2012, 40(4):1122-1128.

7. Herridge MS, Cheung AM, Tansey CM, Matte-Martyn A, Diaz-Granados N, Al-Saidi F, Cooper AB, Guest CB, Mazer CD, Mehta S et al: One-year outcomes in survivors of the acute respiratory distress syndrome. N Engl J Med 2003, 348(8):683-693.

8. Iwashyna TJ, Ely EW, Smith DM, Langa KM: Long-term cognitive impairment and functional disability among survivors of severe sepsis. JAMA 2010, 304(16):1787-1794.

9. Lipshutz AK, Gropper MA: Intensive Care Unit-acquired Muscle Weakness: An Ounce of Prevention Is Worth a Pound of Cure. Anesthesiology 2016, 124(1):7-9.

10. Casaer MP: Muscle weakness and nutrition therapy in ICU. Curr Opin Clin Nutr Metab Care 2015, 18(2):162-168.

11. De Jonghe B, Sharshar T, Lefaucheur JP, Authier FJ, Durand-Zaleski I, Boussarsar M, Cerf C, Renaud E, Mesrati F, Carlet J et al: Paresis acquired in the intensive care unit: a prospective multicenter study. JAMA 2002, 288(22):2859-2867.

12. Fan E, Cheek F, Chlan L, Gosselink R, Hart N, Herridge MS, Hopkins RO, Hough CL, Kress JP, Latronico N et al: An official American Thoracic Society Clinical Practice guideline: the diagnosis of intensive care unit-acquired weakness in adults. Am J Respir Crit Care Med 2014, 190(12):1437-1446.

13. Bunnell A, Ney J, Gellhorn A, Hough CL: Quantitative neuromuscular ultrasound in intensive care unit-acquired weakness: A systematic review. Muscle Nerve 2015, 52(5):701-708.

14. Puthucheary ZA, McNelly AS, Rawal J, Connolly B, Sidhu PS, Rowlerson A, Moxham J, Harridge SD, Hart N, Montgomery HE: Rectus Femoris CrossSectional Area and Muscle Layer Thickness: Comparative Markers of Muscle Wasting and Weakness. Am J Respir Crit Care Med 2017, 195(1):136-138.

15. Puthucheary ZA, Rawal J, McPhail M, Connolly B, Ratnayake G, Chan P, Hopkinson NS, Phadke R, Dew T, Sidhu PS et al: Acute skeletal muscle wasting in critical illness. JAMA 2013, 310(15):1591-1600.

16. Parry SM, El-Ansary D, Cartwright MS, Sarwal A, Berney S, Koopman R, Annoni R, Puthucheary Z, Gordon IR, Morris PE et al: Ultrasonography in the intensive care setting can be used to detect changes in the quality and quantity of muscle and is related to muscle strength and function. $J$ Crit Care 2015 , 30(5):1151 e1159-1114.

17. Palakshappa JA, Reilly JP, Schweickert WD, Anderson BJ, Khoury V, Shashaty MG, Fitzgerald D, Forker C, Butler K, Ittner CA et al: Quantitative peripheral muscle ultrasound in sepsis: Muscle area superior to thickness. J Crit Care 2018, 47:324-330.

18. Puthucheary ZA, Phadke R, Rawal J, McPhail MJ, Sidhu PS, Rowlerson A, Moxham J, Harridge S, Hart N, Montgomery HE: Qualitative Ultrasound in Acute Critical Illness Muscle Wasting. Crit Care Med 2015, 43(8):1603-1611.

19. Cartwright MS, Kwayisi G, Griffin LP, Sarwal A, Walker FO, Harris JM, Berry MJ, Chahal PS, Morris PE: Quantitative neuromuscular ultrasound in the intensive care unit. Muscle Nerve 2013, 47(2):255-259. 
20. Patejdl R, Walter U, Rosener S, Sauer M, Reuter DA, Ehler J: Muscular Ultrasound, Syndecan-1 and Procalcitonin Serum Levels to Assess Intensive Care Unit-Acquired Weakness. Can J Neurol Sci 2019, 46(2):234-242.

21. Witteveen E, Sommers J, Wieske L, Doorduin J, van Alfen N, Schultz MJ, van Schaik IN, Horn J, Verhamme C: Diagnostic accuracy of quantitative neuromuscular ultrasound for the diagnosis of intensive care unit-acquired weakness: a cross-sectional observational study. Ann Intensive Care 2017, 7(1):40.

22. Stevens RD, Marshall SA, Cornblath DR, Hoke A, Needham DM, de Jonghe B, Ali NA, Sharshar T: A framework for diagnosing and classifying intensive care unit-acquired weakness. Crit Care Med 2009, 37(10 Suppl):S299-308.

23. Sessler CN, Gosnell MS, Grap MJ, Brophy GM, O'Neal PV, Keane KA, Tesoro EP, Elswick RK: The Richmond Agitation-Sedation Scale: validity and reliability in adult intensive care unit patients. Am J Respir Crit Care Med 2002, 166(10):1338-1344.

24. Mourtzakis M, Wischmeyer P: Bedside ultrasound measurement of skeletal muscle. Curr Opin Clin Nutr Metab Care 2014, 17(5):389-395.

25. Galindo Martin CA, Monares Zepeda E, Lescas Mendez OA: Bedside Ultrasound Measurement of Rectus Femoris: A Tutorial for the Nutrition Support Clinician. J Nutr Metab 2017, 2017:2767232.

26. Grimm A, Teschner U, Porzelius C, Ludewig K, Zielske J, Witte OW, Brunkhorst FM, Axer H: Muscle ultrasound for early assessment of critical illness neuromyopathy in severe sepsis. Crit Care 2013, 17(5):R227.

27. Li J, Fine J: On sample size for sensitivity and specificity in prospective diagnostic accuracy studies. Stat Med 2004, 23(16):2537-2550.

28. Connolly B, MacBean V, Crowley C, Lunt A, Moxham J, Rafferty GF, Hart N: Ultrasound for the assessment of peripheral skeletal muscle architecture in critical illness: a systematic review. Crit Care Med 2015, 43(4):897-905.

29. Turton P, Hay R, Taylor J, McPhee J, Welters I: Human limb skeletal muscle wasting and architectural remodeling during five to ten days intubation and ventilation in critical care - an observational study using ultrasound. BMC Anesthesio/ 2016, 16(1):119.

30. Annetta MG, Pittiruti M, Silvestri D, Grieco DL, Maccaglia A, La Torre MF, Magarelli N, Mercurio G, Caricato A, Antonelli M: Ultrasound assessment of rectus femoris and anterior tibialis muscles in young trauma patients. Ann Intensive Care 2017, 7(1):104.

31. Mueller N, Murthy S, Tainter CR, Lee J, Riddell K, Fintelmann FJ, Grabitz SD, Timm FP, Levi B, Kurth T et al: Can Sarcopenia Quantified by Ultrasound of the Rectus Femoris Muscle Predict Adverse Outcome of Surgical Intensive Care Unit Patients as well as Frailty? A Prospective, Observational Cohort Study. Ann Surg 2016, 264(6):1116-1124.

32. Greening NJ, Harvey-Dunstan TC, Chaplin EJ, Vincent EE, Morgan MD, Singh SJ, Steiner MC: Bedside assessment of quadriceps muscle by ultrasound after admission for acute exacerbations of chronic respiratory disease. Am J Respir Crit Care Med 2015, 192(7):810-816.

\section{Figures}

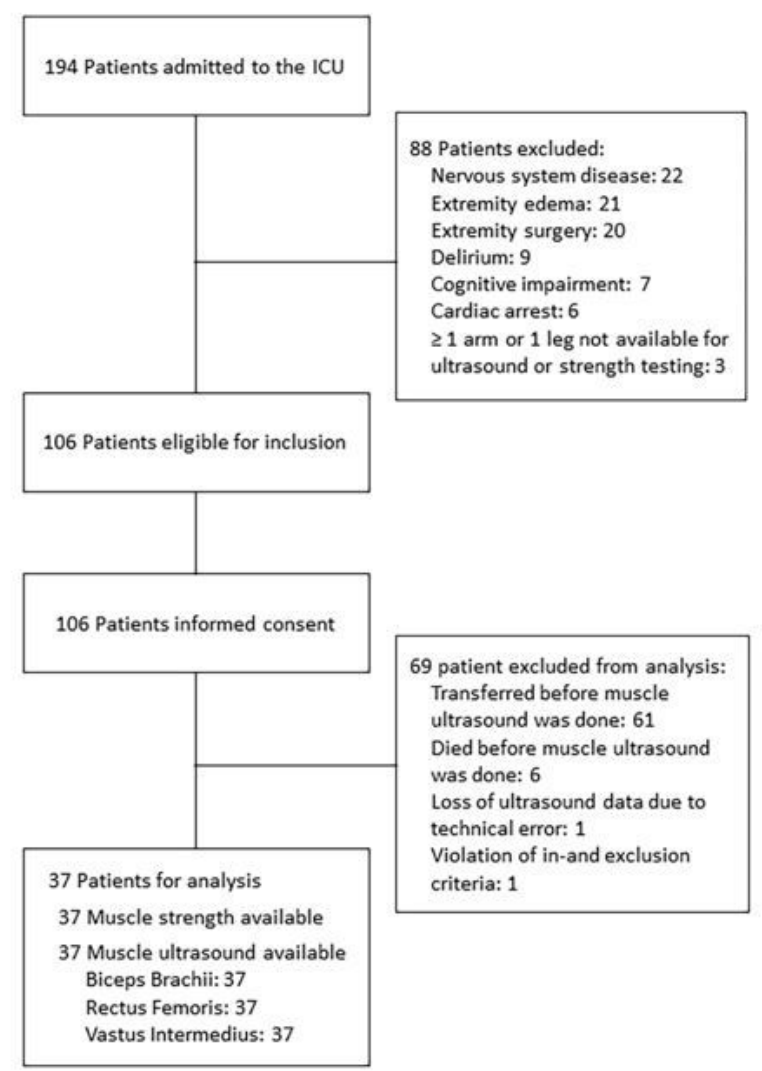

Figure 1 
Flowchart representing screening and inclusion of patients.

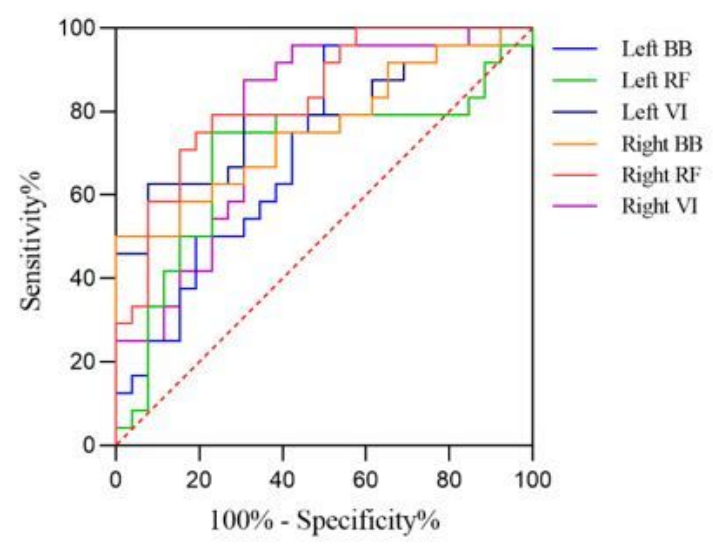

Figure 2

ROC curves for $\triangle T H$ of muscles

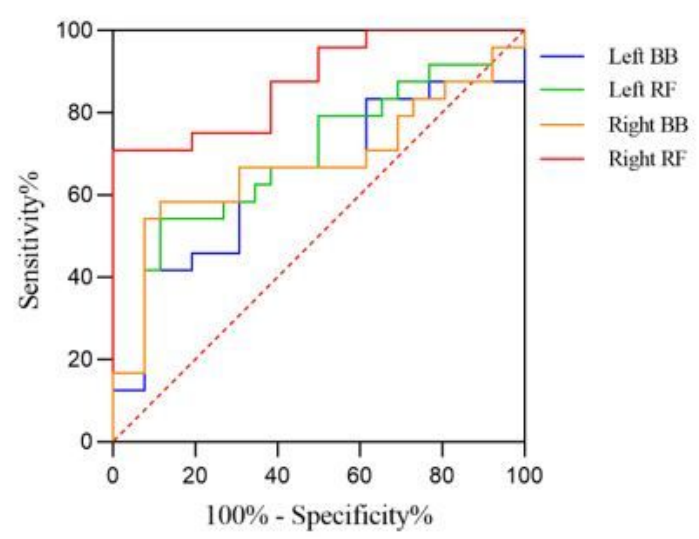

Figure 3

ROC curves for $\triangle \mathrm{CSA}$ of muscles 